(3) In quadrivalents (lower two lines of Fig. I) $e$ is the most common form, $b, c, d$, and $f$ being rare. Thus junctions of two ends are as common as those of four or three, and free ends are abundant.

(4) In agreement with these results is the fact that the frequency of separate single chromosomes at the first metaphase is least in the diploids, where they are rare. It is greater in triploids, where separate chromosomes may sometimes occur almost in every other cell. In tetraploids, however, separate chromosomes are usually so common that it often requires a search to find a cell with $n$ quadrivalents.

\section{John Belling.}

Carnegie Institution of Washington, Cold Spring Harbor, N.Y.

\section{Scientific Neglect of the Mas d'Azil.}

THE other day in the course of an automobile tour I visited the Mas d'Azil. I would like to direct the attention of the readers of NATURE, and particularly of those with money and organising power, to the very unsatisfactory state of affairs in this beautiful and incomparable treasure-house of archæological material. Practically there is no control, no protection and no organised excavation whatever at Mas d'Azil. There are masses of valuable material, but none of it is being worked at properly. Much of it, I fear, is being wasted and muddled up. There is a' guide,' a pleasant untrained man, who pokes about in the caves, digs out bones which, as he remarks, fall to pieces, and presents the casual visitor with teeth or flint implements he has found in his own researches. He has no regular salary. He has to supplement his fees and tips by other work. Occasionally, isolated individuals obtain permission from the municipality and prod in the rocks and extract this or that and publish their 'results,' according to their lights. There is a small useless museum without labels or arrangement at the Mairie. The financial situation forbids the hope of Government direction. The essential trouble seems to be the want of funds. From Mas d'Azil came some of the most beautiful and interesting objects in the admirably arranged museum in Toulouse; the carved horse head and other carvings and the painted pebbles from this site are well known. One would not need to go outside the scientific ability available in the region if money were forthcoming to mobilise it for the proper exploitation of these priceless deposits.

$$
\text { H. G. Wells. }
$$

\section{The Eggs of the Pilot-fish (Naucrates ductor).}

In Ann. Mag. Nat. Hist. (9) 2, p. II4, I9I8, Dr. Gilchrist described the egg of the Pilot-fish as having a long filament attached to the pole opposite the micropyle, and he states that it serves to attach the egg to the wall of the ovary. Further, the egg was stated to be oval, with a large perivitelline space, but without any oil globule. From the presence of the filaments on the eggs, Dr. Gilchrist presumed that the eggs were attached to floating objects and offered a plausible explanation of the well-known, but hitherto unexplained, habits of the Pilot-fish.

In November last a ripe female of the Pilot-fish was received at this Museum, and I was able to obtain a large quantity of eggs. To my astonishment these eggs differed from those described by Dr. Gilchrist in the two main characteristics mentioned: they possessed no trace of any filaments, but a distinct oil globule was present. On the other hand, they agreed in their more or less oval shape and the large perivitelline space. They floated in sea water. An examination of the ovary disclosed no "grape-like clusters" such as Dr. Gilchrist found, but only the normal structure.

In the case of such a well-known fish as the Pilotfish, misidentification can be excluded. Another very unlikely possibility occurred to me, namely, that by a slip of the pen Naucrates ductor was written instead of Echeneis naucrates, the latter fish also being known in these waters as 'Lootsman' and found in association with sharks. To be certain, I examined the Museum material of this and allied species, the eggs of which are apparently still undescribed. Only two females with ripe ova were found and these lent no support to the suggestion of a misnomer having occurred. The ovary showed normal structure and the loose ripe eggs showed no trace of filaments.

The explanation of these diametrically opposed observations can only be found by the study of further material, and it is in the hope that ichthyological students will take the opportunity of examining fresh material and material preserved in Museums, that this letter is written.

South African Museum,

KEPPEL H. Barnard.

Cape Town, July rg.

\section{Spinning Electrons.}

IN view of the recent correspondence in NATURE concerning the spinning electron, it may be of interest to consider the effect of free electrons possessing a magnetic moment on the magnetic susceptibility of metals.

If the magnetic moment of the free electron is one Bohr magneton, and the orientation of its axis with respect to an external magnetic field is assumed to be given by the Boltzmann distribution law, then the paramagnetic contribution to the molecular susceptibility (on the basis of the Pauli-Sommerfeld averaging) will be $1378 \times 10^{-6} P$ at $273^{\circ} \mathrm{K}$, where $P$ is the ratio of the number of free electrons per grammolecule to Avogadro's number. Copper and silver have molecular susceptibilities of $-5.7 \times 10^{-6}$ and $-20.5 \times 10^{-6}$ respectively. The contribution to the diamagnetic susceptibility of such atoms or ions as may exist in the metal can scarcely be more than $-29.8 \times \mathrm{IO}^{-6}$ (the molecular susceptibility of $\mathrm{Rb}^{+}$) in the case of copper, and $-37 \times 10^{-6}\left(\mathrm{Cs}^{+}\right)$in silver.

It must be remembered, in addition, that the normal atom in copper and silver has a magnetic moment of one Bohr magneton. Unless we assume that in the solid metal these elements exist in a form very different from their normal atomic state, and further, that the number of free electrons does not exceed 3 per cent. of the total number of atoms, the hypothesis of the spinning electron leads to some difficulties in understanding the diamagnetism of these metals, and of the alkalis as well.

Since the contribution to the susceptibility of the spinning free electrons would obey the Curie law, namely, that the paramagnetic susceptibility is inversely proportional to the absolute temperature, any considerable contribution to the susceptibility would therefore show itself in a temperature variation in the total diamagnetic susceptibility of a much higher order than that actually found by experiment.

Columbia University, I. I. RABI.

New York City, June 22. 